Studies in Second Language Acquisition, 2014, 0, 1-12.

doi:10.1017/S0272263114000138

\title{
BEYOND SEGMENTS
}

\author{
Prosody in SLA
}

\section{Ineke Mennen \\ Bangor University}

Esther de Leeuw

Queen Mary, University of London

Mastering the pronunciation of a second language (L2) is considered extremely difficult, and few individuals succeed in sounding like a native speaker when learning a L2 in adulthood (Bongaerts, Van Summeren, Planken, \& Schils, 1997; Scovel, 2000). Successful L2 pronunciation involves not only learning how to authentically produce all the individual sounds of the target language but also the acquisition of the L2's unique prosody, such as its intonation, stress, rhythm, tone, and tempo.

Transfer from the first language (L1) is thought to be particularly persistent in prosody; L1 prosodic influences can remain present even after years of experience with the L2 (Mennen, 2004; Pickering, 2004). Research suggests that nontargetlike prosody in a L2 plays an important and independent role in the perception of foreign accentedness and in native-listener judgments of comprehensibility (Jilka, 2000; Magen, 1998; Munro, 1995; Trofimovich \& Baker, 2006). Some research even suggests that prosody is more important than segments in such perceptions

The idea of putting together this special issue originated during a workshop on L2 prosody at Bangor University organized by the first author. We would like to thank all participants of that workshop for the enthusiasm with which this idea was received. We wish to express our sincere thanks to all of the authors for their excellent contributions to this issue and to the SSLA editorial team for all their help in bringing this issue to completion. We extend a particular thank-you to the Arts and Humanities Research Council for providing the first author with the time to help shape this special issue through a fellowship $(\mathrm{AH} / \mathrm{J} 000302 / 1)$.

Correspondence concerning this article should be addressed to Ineke Mennen, Centre for Research on Bilingualism, Bangor University, 37-41 College Road, Bangor, Gwynedd LL57 2DG, United Kingdom. E-mail: i.mennen@bangor.ac.uk 
(e.g., Anderson-Hsieh, Johnson, \& Koehler, 1992; Boula de Mareüil \& Vieru-Dimulescu, 2006; Carmichael, 2000; Magen, 1998). Despite this, and despite the fact that there is a large and growing body of research on prosody in mainstream phonetics and phonology, there has-until recently-been comparatively little investigation of prosody within SLA (Gut, 2009; Mennen, 2004; Piske, MacKay, \& Flege, 2001). For example, a survey of major international journals in L2 acquisition between 1969 and 2008 (Gut, 2009) showed that of 133 empirical studies on L2 phonology, only 17 pertained to prosody.

Recent years have, however, seen a growing interest in the prosodic aspects of SLA, and attempts are now being made to develop new or to extend existing models to account for the prosodic aspects of speech learning in SLA. We therefore believe that the time is ripe for this special issue, which moves beyond the segmental level of speech to focus on prosody in SLA.

\section{WHAT IS PROSODY?}

It's not what you say; it's how you say it. Everyone has heard these words, or perhaps even said them themselves. Most likely, if one attempted to explain exactly how the particular words in question were said, it would be difficult to do so. They may have been articulated quickly or slowly, with a high or low pitch, loudly or quietly, or with a combination of these characteristics. When trying to describe the manner in which something is said, one is, in most cases, attempting to describe the prosody of an individual's speech.

The term prosody has been defined in different ways across various research disciplines. Some use the term in a rather abstract way "to refer to the phonological organization of segments into higher-level constituents and to the pattern of relative prominences within these constituents" (Shattuck-Hufnagel \& Turk, 1996, p. 196). Others use it to refer to "the realization itself, that is, [they] effectively use it as a synonym for suprasegmental features" (Cutler, Dahan, \& van Donselaar, 1997, p. 142), such as pitch, tempo, loudness, or duration. Adherents of the second definition would, for example, not "consider the structure of syllables to fall within the study of prosody" (Cutler et al., 1997, p. 142). Conversely, adherents of the first definition would, for instance, not accept paralinguistic qualities, such as information about a speaker's emotional state (e.g., whether the speaker is happy or sad), identity (e.g., gender, age), attitude (e.g., whether the speaker is friendly or hostile), or the social or regional group he or she belongs to (or aspires to belong to), to be channeled through prosody. Perhaps the most common definition of prosody falls somewhere between these two extremes, merging both the higher level organization and the phonetic reflexes of 
this organization. This definition explains prosody as "the linguistic structure which determines the suprasegmental properties of utterances" (Cutler et al., 1997, p. 142). This definition is the one we adopt in this introduction. However, as none of the articles in this special issue is concerned with paralinguistic aspects of prosody, this introduction focuses on the linguistics aspects of prosody, although we acknowledge that this separation is artificial, as both linguistic information and paralinguistic information are transported through the same acoustic medium.

Prosody is present in every spoken utterance, such that any utterance-no matter how short or in which language it is spokenmust have a certain duration, loudness, or pitch (Cutler et al., 1997). It is therefore not surprising that prosody plays a very central role in human communication. It is used to convey a variety of types of information. For instance, prosody can clarify the grammatical or discourse function of an utterance, such that, if the phrase Mile End is in London is said with a falling pitch, it often (although not always) represents a statement, whereas if the same sequence of words is said with a rising pitch, it often indicates a question. Similarly, falling pitch, in combination with lengthening of the final syllable, may be an indicator that the speaker has finished his or her turn. Rising pitch or a high-level pitch on the last syllable in Mile End is in London may indicate that the speaker wants to continue speaking and is not ready to hand over his or her turn to another speaker. In this example, prosody is used to give information about the dialogue. Another function of prosody is to make important information stand out. If one were to say Mile End is in LONDON, it sounds as if London is contrasted with something else, such as Mile End is in London, not Birmingham. This emphasis or focusing of the attention on the word London is cued (at least in English) primarily by acoustic patterns of fundamental frequency (F0), duration, and amplitude (e.g., Lehiste, 1970). These acoustic cues are perceived by listeners as pitch, length, and loudness, such that the stressed syllable of the emphasized word is perceived as higher, longer, and louder in comparison to the words and syllables that are not emphasized. Other acoustic cues that are known to be important in the perception of prominence are spectral modulations (including formant structures), vowel quality, and vowel reduction (Shattuck-Hufnagel \& Turk, 1996), and the various acoustic parameters are thought to interact with one another to signal prominence.

In a similar way, prosody can also be used to convey lexical meaning. In many languages, words can be distinguished on the basis of lexical stress, such that the English word FOREbear is an ancestor, whereas forBEAR is a verb meaning to refrain from or to abstain (examples are taken from Cutler et al., 1997). Despite the spelling difference, there are no segmental differences between these words; they only differ in their 
stress placement. In such words, English listeners tend to use the aforementioned primary acoustic cues in perception and to judge syllables as stressed when they are of longer duration, have higher pitch, and are louder than other syllables (Cutler, 2005). Words that differ only in stress placement are, however, rather rare. In English, only a few dozen minimal stress pairs exist (Cutler \& Pasveer, 2006). Typically, syllables that differ in stress also differ in vowel quality; for example, in the words CONtest and conTEST, the first syllable (con-) of the word CONtest has a full vowel, whereas in conTEST that vowel is reduced. In such cases, listeners also attend to vowel quality (alongside the cues of duration, pitch, and loudness) to determine whether a syllable is stressed.

A final function of prosody that we discuss here is that of grouping constituents that belong together. This particular function of what we call prosodic phrasing is closely related to syntax. Through prosody, words can be grouped into larger chunks of speech to signal major syntactical boundaries or paragraph boundaries and to disambiguate utterances of which the syntax is ambiguous. To give an example, the sentence When you learn gradually you worry more could be divided, for instance, into the chunks when you learn and gradually you worry more or the chunks when you learn gradually and you worry more. These chunks or groupings are signaled prosodically by means of pausing, lengthening of the syllable at the end of a phrase, a change in pitch direction, or any combination of these. The actual location of the prosodic boundaries corresponds to a different meaning: The location of the boundary in the first example (When you learn, gradually you worry more) implies that the worrying increases gradually, whereas the second example (When you learn gradually, you worry more) refers to gradual learning (examples are taken from Price, Ostendorf, ShattuckHufnagel, \& Fon, 1991). Although prosodic phrasing often mirrors syntactical structure, not all syntactic boundaries are signaled by prosody, and disfluencies can also occur at places that do not coincide with syntactical boundaries.

\section{PROSODY IN SLA}

Given the complexity and the multitude of functions of prosody, it is perhaps not surprising that prosodic properties are notoriously difficult to learn (Atoye, 2005; Cruz-Ferreira, 1989) and are often seen as "the final hurdle, which a vast majority of speakers of English as a foreign language never manage to cross" (Banjo, 1979, p. 12; although this seems to be an observation that holds for the L2 acquisition of languages other than English as well). Indeed, learning how to produce L2 prosody is complicated, as languages differ not only in prosodic structure but also in how prosodic properties are implemented in terms of 
their suprasegmentals such as pitch, tempo, loudness, or duration (e.g., Cutler et al., 1997). For example, languages are thought to differ intonationally along four dimensions (Ladd, 1996): (a) the systemic dimension-that is, the inventory of structural elements (pitch accents and boundary phenomena); (b) the functional dimension-that is, how these elements are used to signal certain linguistic functions (such as interrogativity or focus); (c) the distributional dimension-that is, how often the different structural elements are used and how they combine; and (d) the realizational dimension-that is, the phonetic implementation of these structural elements, which describes the way in which the systemic elements of intonation are phonetically realized (e.g., how the pitch accents align with the segments, and what their relative height is in a given utterance). Therefore, to master the intonation of a language, the L2 learner not only needs to master its structural elements (pitch accents and boundary tones) but also needs to learn how these structural elements are phonetically realized, how they combine into contours, and how they are used to signal meaning. Similarly, when learning how to make certain information stand out in a L2, the learner has to be aware of which linguistic means are used for marking information structure in that language-whether, to highlight certain information, it uses word order (e.g., Greek), uses a distinct pitch accent (e.g., Portuguese), or places a pitch accent on the constituent in focus and deaccents any information that follows (e.g., Germanic languages). Acquiring other prosodic properties, such as rhythm, stress, or lexical tone, must invoke similar difficulties for the L2 learner, because languages vary in equally complex ways in terms of how they instantiate these prosodic properties.

Although there is general agreement that L2 learners have significant and continuing problems learning to produce nonnative prosody, there is far less agreement as to what the underlying cause or causes of these problems are. In an attempt to identify the nature of the problem, one line of research in the field of L2 prosody has therefore been to characterize the difficulties that learners experience. As previously described, a possible source of the difficulty may be the complexity and multidimensionality of prosody. Another assumption that is generally made is that the difficulty is perceptual in nature or related to difficulties in the processing of prosody. As with segments, it is generally assumed that the perception of L2 prosody is, to a large extent, influenced by or filtered through the prosodic regularities of the L1. However, experimental studies investigating prosody perception and processing have only recently started to appear, addressing, among other topics, how tone (Gandour, 1983; So \& Best, 2010; Wang, Jongman, \& Sereno, 2003), stress (Altmann, 2006; Dupoux, Pallier, Sebastian, \& Mehler, 1997; Dupoux, Sebastián-Gallés, Navarrete, \& Peperkamp, 2008; Tremblay, 2008), and intonation (A. Chen, Gussenhoven, \& Rietveld, 2004; Cruz-Ferreira, 1987; 
Grabe, Rosner, García-Albea, \& Zhou, 2003; Shen, 1990) are perceived. Indeed, findings suggest that most difficulties learners experience when producing L2 prosody appear to be perceptually motivated. However, results also suggest that not all prosodic difficulties can be attributed to the transfer of perceptual strategies from the L1, as learners sometimes exhibit prosodic strategies that exist neither in the L1 nor in the L2 (Archibald, 1997). In fact, good prosodic perception skills in the L2 do not necessarily lead to good production of L2 prosody. Similarly, it is possible for learners to perform poorly in perception yet to display targetlike prosody in L2 production (Altmann, 2006). This suggests that prosodic difficulties are not due solely to problems in L2 perception, and other causes, such as motor production constraints or problems with the storage of prosodic information in long-term memory, may also need to be considered.

Alongside attempts to determine the nature of the persistent difficulties L2 learners experience with L2 prosody, research has also focused on how nontargetlike prosody is perceived and interpreted by native listeners. Much of this research is concerned with the contribution of prosody to the perception of foreign accent. Studies repeatedly show that prosodic phenomena contribute to foreign accent detection (e.g., Anderson-Hsieh et al., 1992; Jilka, 2000; Magen, 1998; Munro, 1995; Trofimovich \& Baker, 2006; Van Els \& de Bot, 1987). Although the majority of these studies focused on the role of intonation in the perception of foreign accent, there is also evidence for the influence of other prosodic properties, such as pitch range and stress (Kang, 2010), speaking rate (Munro \& Derwing, 2001), timing (Tajima, Port, \& Dalby, 1997), and phonotactics and rhythm (e.g., Carter, 2005; Grenon \& White, 2008; Gut, 2003; White \& Mattys, 2007). Much of the work in this area has made use of digital signal processing and manipulation techniques. For instance, the technique of low-pass filtering suppresses the segmental information of speech (rendering it unintelligible) but preserves most prosodic properties. Such techniques have also made it possible to study the relative contribution of prosody and segments to the perception of foreign accent. As yet, findings are inconclusive, with some studies showing segments to be more important (Boula de Mareüil, Marotta, \& Adda-Decker, 2004) and others reporting either an equal role for prosody and segments (Munro, 1995) or a larger role for prosody in foreign accent perception (e.g., Anderson-Hsieh et al., 1992; Boula de Mareüil \& Vieru-Dimulescu, 2006; Carmichael, 2000; Magen, 1998). Foreign accented speech need not necessarily affect intelligibility or comprehensibility. Even heavily accented speech, whether from nontargetlike segments or nontargetlike prosody (or indeed a combination of the two), can be highly intelligible (Derwing \& Munro, 1997; Munro \& Derwing, 1995). To date, the research examining the contribution of prosody to intelligibility or comprehensibility has been quite limited. A study by Tajima et al. (1997) showed that 
correcting prosodic (in this case rhythmic) properties of L2 speech led to improved intelligibility of the speakers, whereas Munro and Derwing (1995) and Derwing and Munro (1997) found that prosodic deviances of L2 speech negatively influenced both intelligibility and comprehensibility. Braun, Lemhöfer, and Mani (2011) showed that deviances in the languagespecific implementation of stress (i.e., by placing stress on the correct syllable but using the wrong acoustic cues) may also affect speech comprehension. Similarly, presenting native speakers with nonnative intonation contours was found to slow down lexical access, showing that nonnative prosody affects comprehensibility (Braun, Dainora \& Ernestus, 2011). Research on the effects of nontarget prosody on communication ability will ultimately benefit the L2 learner, as the goal of any learner is to yield successful communication in the L2. Research of this kind will highlight which prosodic aspects promote intelligibility and will identify those deviations that are detrimental to communication. This information is bound to be valuable to foreign language teaching, in which the focus in the area of phonology has, until recently, been on the teaching of segmentals (Derwing, 2008; Munro, 2008).

\section{THE SPECIAL ISSUE}

The articles included in this special issue document a variety of cuttingedge approaches to investigating prosody in SLA. The articles cover the $\mathrm{L} 2$ acquisition of a range of prosodic phenomena, such as tone, intonation, and rhythm, in a variety of L1 and L2 combinations and proficiency levels.

We begin the issue with a study on the cross-language perception of tone (So \& Best). Although all languages use pitch for communicative purposes, some languages and dialects additionally use pitch to distinguish the lexical or grammatical meaning of otherwise identical words (Ladd, 1996). On this basis, languages are often divided into tone languages (which systematically use tone to express lexical or grammatical distinctions) and nontone languages (which use pitch for intonational or pragmatic purposes). The few studies on L2 acquisition of lexical tones suggest that tones are difficult to acquire by speakers of nontone languages (e.g., G. T. Chen, 1974; Miracle, 1989; Shen, 1989). These studies show that L2 learners often produce errors in either the register (i.e., they are too high or too low) or pitch direction (e.g., substituting a level tone with falling pitch) of tones. In terms of perception, the majority of studies have been confined to crosslanguage (rather than L2) studies, which examine whether speakers of tone and nontone languages differ in the way they perceive and process lexical tones. Findings generally suggest that the perception of nonnative tones is substantially influenced by the listeners' native language (Gandour, 1983; Lee, Vakoch, \& Wurm, 1996; Wayland \& Guion, 2004). 
In the first article of the special issue, So and Best investigate how listeners of nontone languages perceive nonnative lexical tones in connected speech, an issue that has largely escaped detailed attention to date. So and Best investigate how listeners of two nontone languages, Australian English and French, perceive Mandarin tones in a sentence environment and how they categorize the four Mandarin tones into their native sentence intonation categories. They argue that lexical stress differences between French and English listeners may have affected their ability to perceive the phonetic differences between the Mandarin Tone 3 (low falling) and Tone 4 (high falling). Speakers of French, which lacks lexical stress, are able to perceive the differences, whereas speakers of English, a lexical stress language, are not. So and Best argue that the presence of lexical stress may have led English listeners to perceive the tones as conveying both lexical stress and sentencelike intonation.

The next article targets the L2 acquisition of speech rhythm (Li \& Post). Traditionally, languages have been divided, according to their perceived rhythmical differences, into stress-timed versus syllabletimed languages. In stress-timed languages (e.g., English), stress was thought to occur at approximately equal intervals in time, whereas in syllable-timed languages (e.g., French), each syllable was thought to be of equal duration. This has led to the search for quantitative measures that could support the percept of a rhythmic distinction between languages. These rhythm metrics have provided empirical evidence in support of the percept of rhythm class that is scalar rather than categorical. Li and Post exploit these rhythmical differences between languages to examine the acquisition of rhythm in Mandarin Chinese and German learners of English at different proficiency levels. They investigate to what extent rhythm metrics as well as the prosodic properties of accentual lengthening and phrase-final lengthening that contribute to speech rhythm reflect different levels of L2 proficiency. Their analyses show that accentual lengthening and phrase-final lengthening as well as most rhythm metrics discriminated well between L2 proficiency levels. They show that both transfer effects and universal constraints play a role in the acquisition of L2 speech rhythm, and they argue for the multisystemic nature of L2 prosodic acquisition in which various prosodic properties may interact with and depend on one another in the acquisition process.

Speech rhythm is also one of the prosodic phenomena investigated in the third article of this special issue, by Gabriel and Kireva, which focuses on the Spanish-Italian contact variety spoken in Buenos Aires (Porteño). It probes to what extent patterns of rhythm and intonation, which are typical of Italian, show up in Porteño and in the L2 Castilian Spanish produced by Italian native speakers. Their study reveals that the rhythm metrics displayed in Italian surface in both Porteño and L2 
Castilian Spanish speech (spoken by native Italian speakers). This finding supports the hypothesis that the change in Porteño prosody is a result of transfer from the L1 that occurred when Italian immigrants learned Spanish as a L2 in Argentina. The findings for intonation, however, only partially support the transfer hypothesis for Porteño Spanish. Contemporary Porteño is found to always realize yes-no questions with a falling pitch movement rather than differentiating the different pragmatic meanings conveyed by Castilian Spanish through different yes-no question contours. Therefore, Gabriel and Kireva argue that the fact that contemporary Porteño has only one pitch contour in interrogatives may be the result of overgeneralization due to markedness in the L2 acquisition of this variability.

The next two studies in this special issue target the production of intonation in SLA. Gut and Pillai probe the potential crosslinguistic influences of the prosodic systems of Malay speakers of L2 English, by focusing on their marking of information structure. The study investigates the prosodic correlates of focus and givenness both in Malay and in the English produced by native speakers of Malay. To this end, word pairs of given and new information are compared in terms of their syllable duration, type of pitch accent, phonetic realization of the rise, and pitch peak alignment. They find that, although in most of the measures no differences are observed between the Malay and English spoken by the speakers, not all patterns of marking new and given information in the speakers' L2 English can be explained solely by crosslinguistic influences. In particular, they find that speakers tend to alter some prosodic features (e.g., in the type of pitch accents) in their L2 and produce error patterns (e.g., not deaccenting the given information) that are commonly observed in the speech of L2 speakers from different L1 backgrounds; these findings-with those of Li and Post-suggest that universal constraints may play a role in the acquisition of information structure in a L2.

The study by Mennen, Schaeffler, and Dickie focuses on another aspect of intonation production in SLA-namely, that of pitch range produced by German learners of L2 English of moderate to advanced proficiency. They base their study on prior research that found that the crosslanguage differences between native English and German speakers are position sensitive in nature. That is, the cross-language differences depend on where in an intonation contour measures are taken, with a wider range for English speakers in earlier parts but a narrower range in later parts of intonational phrases (Mennen, Schaeffler, \& Docherty, 2012). Their study tests whether German learners of L2 English are sensitive to such position-sensitive differences in the target language or whether they are only able to produce the cross-language differences that are more global in nature. Their results show that the German learners predominantly produce pitch range values that approximate 
the L2 target. The German learners expand their pitch range toward the L2 English target in the early parts of intonation phrases and compress it in later parts, supporting a position-sensitive adaptation toward the target language. Overall, Mennen, Schaeffler, and Dickie argue that the choice of measures may be crucial for determining the underlying cause of the difficulty L2 learners may experience when attempting to adopt language-appropriate pitch range in the L2.

Continuing with the theme of intonation, the final study in this special issue examines the perception and production of sentential English focus by Mandarin and Spanish learners of L2 English. Ortega-Llebaria and Colantoni test the extent to which higher level processing influences L2 perception and the production of focus intonation; they do so by manipulating the levels of access to meaning. Their findings show that, in tasks that facilitate access to meaning (i.e., tasks with an increased level of prosody processing requiring mapping of intonation forms to meaning), more L1 transfer is observed than in tasks with lower levels of prosody processing (i.e., tasks in which access to meaning is not crucial and attention to acoustic cues is sufficient to perform the task). Overall, Ortega-Llebaria and Colantoni argue that, to master the intonation of the target language, the L2 learner not only needs to master its specific melody but also needs to learn how that melodic form matches to meaning in that language. Crucially though, Ortega-Llebaria and Colantoni's article argues that access to meaning and L1 transfer are likely to influence each other.

Received $X X X$

Accepted XXX

AQ7

Final Version Received XXX

\section{REFERENCES}

Altmann, H. (2006). The perception and production of second language stress: A cross-linguistic experimental study (Unpublished doctoral dissertation). University of Delaware, Newark.

Anderson-Hsieh, J., Johnson, R., \& Koehler, K. (1992). The relationship between native speaker judgments of nonnative pronunciation and deviance in segmentals, prosody, and syllable structure. Language Learning, 42, 529-555.

Archibald, J. (1997). The acquisition of English stress by speakers of nonaccentual languages: Lexical storage versus computation of stress. Linguistics, 35, 167-181.

Atoye, R. O. (2005). Non-native perception and interpretation of English intonation. Nordic Journal of African Studies, 14, 26-42.

Banjo, A. (1979). Beyond intelligibility in Nigerian English. In E. Ubahakwe (Ed.), Varieties and functions of English in Nigeria (pp. 7-13). Ibadan: African Universities Press.

Bongaerts, T., Van Summeren, C., Planken, B., \& Schils, E. (1997). Age and ultimate attainment in the pronunciation of a foreign language. Studies in Second Language Acquisition, $19,447-465$.

Boula de Mareüil, P., Marotta, G., \& Adda-Decker, M. (2004). Contribution of prosody to the perception of Spanish/Italian accents. In B. Bel \& I. Marlien (Eds.), Proceedings of 2nd International Conference on Speech Prosody, Nara, Japan (pp. 681-684). Aix-enProvence, France: Université de Provence. 
Boula de Mareüil, P., \& Vieru-Dimulescu, B. (2006). The contribution of prosody to the perception of foreign accent. Phonetica, 63, 247-267.

Braun, B., Dainora, A., \& Ernestus, M. (2011). An unfamiliar intonation contour slows down online speech comprehension. Language and Cognitive Processes, 26, 350-375.

Braun, B., Lemhöfer, K., \& Mani, N. (2011). Perceiving unstressed vowels in foreignaccented English. Journal of the Acoustical Society of America, 129, 376-387.

Carmichael, L. (2000). Measurable degrees of foreign accent: A correlational study of production, perception, and acquisition (Unpublished master's thesis). University of Washington, Seattle.

Carter, P. M. (2005). Prosodic variation in SLA: Rhythm in an urban North Carolina Hispanic community. Penn Working Papers in Linguistics, 11(2), 59-71.

Chen, A., Gussenhoven, C., \& Rietveld, T. (2004). Language specificity in perception of paralinguistic intonational meaning. Language and Speech, 47, 311-349.

Chen, G. T. (1974). The pitch range of English and Chinese speakers. Journal of Chinese Linguistics, 2, 159-171.

Cruz-Ferreira, M. (1987). Non-native interpretive strategies for intonational meaning: An experimental study. In A. James \& J. Leather (Eds.), Sound patterns in second language acquisition (pp. 103-120). Dordrecht: Forus.

Cruz-Ferreira, M. (1989). A test for non-native comprehension of intonation in English. International Review of Applied Linguistics in Language Teaching, 17, 23-39.

Cutler, A. (2005). Lexical stress. In D. B. Pisoni \& R. E. Remez (Eds.), The handbook of speech perception (pp. 264-289). Oxford: Blackwell.

Cutler, A., Dahan, D., \& van Donselaar, W. (1997). Prosody in the comprehension of spoken language: A literature review. Language and Speech, 40, 141-201.

Cutler, A., \& Pasveer, D. (2006). Explaining cross-linguistic differences in effects of lexical stress on spoken-word recognition. In R. Hoffmann \& H. Mixdorff (Eds.), Proceedings of the 3rd International Conference on Speech Prosody (pp. 237-240). Dresden: TUD Press.

Derwing, T. M. (2008). Curriculum issues in teaching pronunciation to second language learners. In J. G. Hansen Edwards \& M. L. Zampini (Eds.), Phonology and second language acquisition (pp. 347-369). Amsterdam: Benjamins.

Derwing, T. M., \& Munro, M. J. (1997). Accent, intelligibility, and comprehensibility: Evidence from four L1s. Studies in Second Language Acquisition, 19, 1-16.

Dupoux, E., Pallier, C., Sebastian, N., \& Mehler, J. (1997). A destressing "deafness" in French? Journal of Memory and Language, 36, 406-421.

Dupoux, E., Sebastián-Gallés, N., Navarrete, E., \& Peperkamp, S. (2008). Persistent stress "deafness": The case of French learners of Spanish. Cognition, 106, 682-706.

Gandour, J. (1983). Tone perception in Far Eastern languages. Journal of Phonetics, 11, 149-175.

Grabe, E., Rosner, B. S., García-Albea, J. E., \& Zhou, X. (2003). Perception of English intonation by English, Spanish, and Chinese listeners. Language and Speech, 46, 375-401.

Grenon, I., \& White, L. (2008). Acquiring rhythm: A comparison of L1 and L2 speakers of Canadian English and Japanese. In H. Chan, H. Jacob, \& E. Kapia (Eds.), Proceedings of the 32nd annual Boston University Conference on Language Development (pp. 155-166). Somerville, MA: Cascadilla Press.

Gut, U. (2003). Prosody in second language speech production: The role of the native language. Fremdsprachen Lehren und Lernen, 32, 133-152.

Gut, U. (2009). Non-native speech: A corpus-based analysis of phonological and phonetic properties of L2 English and German. Frankfurt: Peter Lang.

Jilka, M. (2000). The contribution of intonation to the perception of foreign accent (Unpublished doctoral dissertation). University of Stuttgart.

Kang, O. (2010). Relative salience of suprasegmental features on judgments of L2 comprehensibility and accentedness. System, 38, 301-315.

Ladd, D. R. (1996). Intonational phonology. Cambridge: Cambridge University Press.

Lee, Y., Vakoch, D., \& Wurm, L. (1996). Tone perception in Cantonese and Mandarin: A cross-linguistic comparison. Journal of Psycholinguistic Research, 25, 527-544.

Lehiste, I. (1970). Suprasegmentals. Cambridge, MA: MIT Press.

Magen, H. (1998). The perception of foreign-accented speech. Journal of Phonetics, 26, 381-400.

Mennen, I. (2004). Bi-directional interference in the intonation of Dutch speakers of Greek. Journal of Phonetics, 32, 543-563. 
Mennen, I., Schaeffler, F., \& Docherty, G. (2012). Cross-language differences in fundamental frequency range: A comparison of English and German. Journal of the Acoustical Society of America, 131, 2249-2260.

Miracle, W. C. (1989). Tone production of American students of Chinese: A preliminary acoustic study. Journal of Chinese Language Teachers Association, 24, 49-65.

Munro, M. J. (1995). Nonsegmental factors in foreign accent. Studies in Second Language Acquisition, 17, 17-34.

Munro, M. J. (2008). Foreign accent and speech intelligibility. In J. G. Hansen Edwards \& M. L. Zampini (Eds.), Phonology and second language acquisition (pp. 193-218). Amsterdam: Benjamins.

Munro, M. J., \& Derwing, T. M. (1995). Foreign accent, comprehensibility, and intelligibility in the speech of second language learners. Language Learning, 45, 73-97.

Munro, M. J., \& Derwing, T. M. (2001). Modeling perceptions of the accentedness and comprehensibility of L2 speech: The role of speaking rate. Studies in Second Language Acquisition, 23, 451-468.

Pickering, L. (2004). The structure and function of intonational paragraphs in native and nonnative speaker instructional discourse. English for Specific Purposes, 23, 19-43.

Piske, T., MacKay, I. R. A., \& Flege, J. E. (2001). Factors affecting degree of foreign accent in an L2: A review. Journal of Phonetics, 29, 191-215.

Price, P. J., Ostendorf, M., Shattuck-Hufnagel, S., \& Fong, C. (1991). The use of prosody in syntactic disambiguation. Journal of the Acoustical Society of America, 90, 2956-2970.

Scovel, T. (2000). A critical review of the critical period research. Annual Review of Applied Linguistics, 20, 213-223.

Shattuck-Hufnagel, S., \& Turk, A. (1996). A prosody tutorial for investigators of auditory sentence processing. Journal of Psycholinguistic Research, 25, 193-247.

Shen, X. S. (1989). Toward a register approach in teaching Mandarin tones. Journal of Chinese Language Teachers Association, 24, 27-47.

Shen, X. S. (1990). Ability of learning the prosody of an intonational language by speakers of a tonal language: Chinese speakers learning French prosody. International Review of Applied Linguistics in Language Teaching, 28, 119-134.

So, C. K., \& Best, C. T. (2010). Cross-language perception of non-native tonal contrasts: Effects of native phonological and phonetic influences. Language and Speech, 53, 273-293.

Tajima, K., Port, R., \& Dalby, J. (1997). Effects of temporal correction on intelligibility of foreign-accented English. Journal of Phonetics, 25, 1-24.

Tremblay, A. (2008). Is second language lexical access prosodically constrained? Processing of word stress by French Canadian second language learners of English. Applied Psycholinguistics, 29, 553-584.

Trofimovich, P., \& Baker, W. (2006). Learning prosody and fluency characteristics of L2 speech: The effect of experience on child learners' acquisition of five suprasegmentals. Applied Psycholinguistics, 28, 251-276.

Van Els, T., \& de Bot, K. (1987). The role of intonation in foreign accent. Modern Language Journal, 71, 147-155.

Wang, Y., Jongman, A., \& Sereno, J. A. (2003). Acoustic and perceptual evaluation of Mandarin tone productions before and after perceptual training. Journal of the Acoustical Society of America, 113, 1033-1044.

Wayland, R., \& Guion, S. (2004). Training English and Chinese listeners to perceive Thai tones: A preliminary report. Language Learning, 54, 681-712.

White, L., \& Mattys, S. (2007). Calibrating rhythm: First language and second language studies. Journal of Phonetics, 35, 501-522. 


\section{Author Queries}

\begin{tabular}{|l|l|}
\hline QA & $\begin{array}{l}\text { The distinction between surnames can be ambiguous, therefore to ensure } \\
\text { accurate tagging for indexing purposes online (eg for PubMed entries), } \\
\text { please check that the highlighted surnames have been correctly identified, } \\
\text { that all names are in the correct order and spelt correctly. }\end{array}$ \\
\hline AQ1 & Missing abstract? \\
\hline AQ2 & Spelled "Fong" (added G) in Refs. Which is correct? \\
\hline AQ3 & Changed "Rietvald" to "Rietveld" (E vs. A), as elsewhere, correct? \\
\hline AQ4 & Missing rec'd lines. \\
\hline AQ5 & Pls provide country of pub. \\
\hline AQ6 & Pls provide country of pub. \\
\hline AQ7 & Please provide history line for this article. \\
\hline
\end{tabular}

